\title{
Twitterature: will social media have an impact on scientific journals?
}

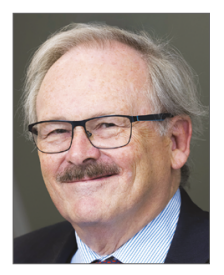

Patrick W. Serruys, Editor-in-Chief; Yoshinobu Onuma, International Associate Editor

Over the last few weeks, I had a Socratic dialogue about the influence of social media on scientific journals with one of my closest scientific collaborators, Dr Yoshi Onuma, International Associate Editor of the journal, as well as our Managing Editor, Sylvie Lhoste, and our publisher, Frederic Doncieux ${ }^{1}$. As we all know, these Socratic dialogues are well known for raising more questions than providing answers.

In parallel, Davide Capodanno, one of the Deputy Editors of EuroIntervention, developed with his usual brio a "catchy" and "sexy" editorial entitled "Twitterature". Obviously, he was tempted - and perhaps even fully seduced - by the so-called "opinion-based medicine" as described by Milton Packer (see below). Davide's contention is straightforward: the electronic speed of the circulation of opinion stemming from individual peered sharing of personal but anecdotal experience is far faster than the peer-reviewed process of analysing the experience of single/multicentre registry/RCTs, which are eventually cited in PubMed. His demonstration concerns information currently available on the introduction of the left distal radial artery (LDRA) approach in our clincal practice. This demonstration is based on personal experience, is factual and educational (see Figure 1 of his editorial)... and, as usual, convincing ${ }^{3}$.

\section{Editorial, see page 959}

As for Yoshinobu Onuma and myself, we take a somewhat different approach to the social media phenomenon, as we try to unravel with our managing editor and publisher the potential impact of social media use on the future scientific status of the journal itself. In doing this, our reflections are also based on anecdotes and social media opinions. To us, both our approach and that of Davide seem complementary and may hopefully trigger and stimulate further reflections amongst our readers. Will the current profound disruption of the publishing space created by the tsunami of social media be responsible for an irreversible metamorphosis of the publishing space? Who knows? One thing is for sure - being Darwinian creatures we will have to adapt and adjust... and evolve. Every human invention (e.g., understanding nuclear atomic fusion and fission) has its bright and dark side. It is up to us to control it.
Specifically, using the scientific topic of the left distal transradial approach (LDTRA) ${ }^{4}$, Davide Capodanno posed a key, burning question: how much more time would it have taken traditional scientific literature to capture the attention of the interventionalist on this clinical approach? Ten years ago, would a similar process have taken place with the implantation of the first biodegradable scaffolds followed by OCT sharing between colleagues - the first images of full resorption, or the first images of dismantling, etc.?

\section{Article, see page 995}

In his conclusion, Davide Capodanno suggests that outcome data should be in scientific journals while techniques, tutorials and clinical cases should be on the web. By being on the web, techniques, tutorials and clinical cases benefit the most from the unlimited multimedia opportunities represented by video and images. As a matter of fact, this is a policy that we have long applied with Europa Digital \& Publishing. In an era of increasingly respected privacy and general data protection regulation (GDPR 2016/679), posting photos of any patient associated with the name of a "twittering" physician could be a major issue. GDPR even impacts on cloud computing regarding the localisation of servers, etc. - you have to know in which country your tweet is physically saved.

As Gary Mintz said, "Our Chinese colleagues are way ahead of us in terms of App-based education, training, and case sharing. They do everything on their phones - in a way that is amazing. For example, a workshop on imaging-guided PCI had 15,000+ viewers. The 'transmissions' (lectures, cases, demonstrations) were high quality both educationally and technically; and they were archived for future viewing. Basically, they have clubs in which they share everything - cases, complications, etc. It is hard to appreciate it unless you experience it. We in the west - North America, South America, Europe, etc. (and even the rest of Asia) have no idea how effective this is." [Personal communication]

In today's world of authors, editor, publishers, we see an explosion of new scientific journals. Between 1999 and 2018, the number of cardiovascular journals has almost doubled. The reason for this phenomenon is unclear. Has the amount of 
cardiovascular information doubled? Has the number of potential authors doubled? Is this due to the impact of social media? Is publishing scientific information a highly profitable activity? Are all future journals going to be approved with the same liberalism by the United States Library of Congress (remembering that PubMed is a US invention, controlled by the National Library of Medicine)?

Another disruptive factor in publishing and editing activities will be the interaction of the journals with social media - or the opposite, the interaction of social media with scientific journals.

In 2017, at the ESC congress, John Jarcho, Deputy Editor of NEJM for the cardiovascular section, challenged the half-century-old Impact Factor allocated to every journal and warned us of the coming impact of social media on the assessment of published science (Figure 1). We do not have the space to describe new bibliometrics, but the readers could simply consult Wikipedia to see the differences between Impact Factor, IQuotient, immediacy index, informetrics, webometrics, H-index and Altmetrics, etc. Bibliometric parameters measure different things such as the influence on the scientific process (IF), percentage of most cited papers (IQ), immediate uptake of the news (immediacy index), news media and social media echo (Altimetrics score). Nevertheless, the IF remains enormously important due to its visibility, the prestige attached to it and its continuing role in academic promotion. Altmetrics, the new technique of assessment, is an amalgam of social media such as YouTube, Twitter, ResearchGate, LinkedIn, BioMed and Facebook, etc. Altmetric will actively emphasise the visibility of new information, but to my mind will not guarantee long-term influence of a new fact - maybe superficial and transient - against a novel discovery with a slow dissemination and penetration, but yet with a permanent and powerful influence on our medical community and on our way of practising medicine. However, I suspect that some of these multi-social media have a potentially pervasive goal based on a foundation other than promoting Science.
Let me illustrate my point of view using the following anecdote. Within weeks following their publication in EuroIntervention, papers usually reach an Altmetric score of 30-60 points, while a publication in Science, for instance, could reach the huge score of 8,000 .

Not so long ago (and I must say, much to our surprise), one manuscript describing a new device and a new treatment modality reached an Altmetric score of 396 points within a few days following its publication. Initially, the paper had been critically reviewed by one of our key reviewers. However, it was eventually saved by the International Editorial Board members.

Puzzled by this sudden burst in the Altmetrics, our managing editor investigated the phenomenon and discovered an orchestrated activation of seven websites that was contributing to the dissemination of the paper. Obviously, the supporting start-up company of this device carefully planned that dissemination strategy. Nothing wrong with this, I guess, yet the question remains whether early social media visibility will promote further investment and clinical studies aiming at evidence-based medicine, that will ultimately result in long-lasting adoption by the clinical community and ultimately offer beneficial treatment for our patients. Only time will tell...

Today, if you want to open a restaurant and be successful, you had better recruit or hire employees who fictively will "fill in" Facebook with eulogistic compliments on the quality of the food and the ambiance of the "restorative" setting, but the visible "impact" will be transient and ephemeral if, in fact, the food is not as delicious as advertised on the Facebook page of my fictive new Facebook friends. We all remember that London's toprated restaurant on TripAdvisor did not exist and was created by a British journalist who "wanted to expose the epidemic of fakery on the internet's most trusted review site" (https://www.vice. com/en_uk/article/434gqw/i-made-my-shed-the-top-rated-restaurant-on-tripadvisor). I have even heard of a new kind of commercial activity that consists of downloading papers in series for the benefit of the authors who failed to be read and cited in PubMed

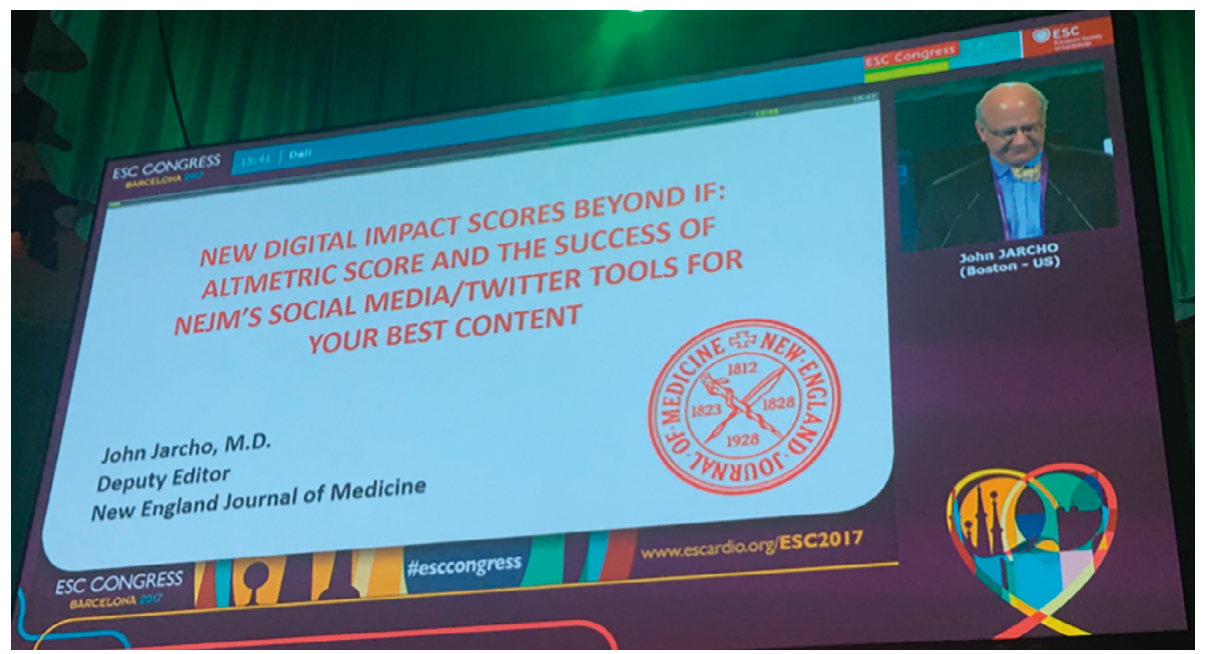

Figure 1. John Jarcho, presentation ESC 2017. 
and who are willing to pay cash in order to become more publicly known. Like bitcoins, are we going to have bit impact factors based on virtual reading and downloading? Who knows? Undeniably, we have entered an era of "fake news" promoted by fast uncontrolled electronic dissemination on virtual advertisements. It is sobering to know that today the median impact factor (the big IF, the true one) of all our scientific papers is still zero. In other words, half of the published papers are never cited, because their quality apparently does not deserve to be cited!

Many journals have embraced the policy of including an editorial about a paper that they are publishing. Although this qualifies as selfcitation according to PubMed, the journal and the authors can claim that the paper has been cited at least once. Then comes the burning question and temptation: should we use (and misuse) Twitter to boost the visibility of the journal? My first reaction is suspicion for something which is uncontrolled and transient and which can make us addictive, consuming a lot of our energy, emotion and time.

I read with great interest an editorial in JACC entitled "Social media and cardiology" by M.N. Walsh'. I am impressed by the interviews with prominent and reliable colleagues and friends: Harlan M. Krumholz, Eric J. Topol, Robert M. Califf and Sunil V. Rao. Their interviews clearly indicate the scientific value of this mode of communication (Twitter). Most of the time, these prominent clinical scientists draw our personal attention to relevant scientific pieces of information recently published that we might have overlooked. This is what I call the noble use of Twitter - one scientist challenging another colleague on the importance of a new emerging fact in a scientific journal. However, there is a less noble use of Twitter.

The noble user of Twitter, Milton Packer, a renowned expert on heart failure, received the Neal Award - considered as the Pulitzer Prize in the business press - and wrote a sarcastic, hilarious column on the Twitter phenomenon ${ }^{6}$. I quote: "Most tweets are simply emotional reactions or an opinion related to some other tweet or some non-tweet event. I tried really hard to find evidence of 'evidence'",

I can confirm that statement from my personal experience. Recently, at the time of the ORBITA trial publication, I saw an intensive exchange of tweets among my fellows in the department, over-reacting in a chain to the tweets of their comrades. I interrupted this ballet of tweets, invited them to join me in my office for a scientific discussion in depth and asked them a simple question: what was the standard deviation of the duration of the exercise test in the two arms of the ORBITA trial'? The response was a long silence of ignorance since none of the fellows had actually read the original publication in The Lancet, but all had consulted on their iPhones multiple social media sources assessing the ORBITA trial in a superficial way.

Let me give you another example. Recently, a fellow drew my attention to a Twitter thread following my presentation on the GLOBAL LEADERS trial in the late-breaking session at the European Society of Cardiology. Twitter disseminated the following "Prof Serruys-Global Leaders: Aspirin is here to stay". I did not tweet back, but e-mailed the "twitterer" with the following question: when and where did I say this? At the time of
GLOBAL LEADERS in February 2011, seven years ago, I tried to eliminate aspirin from the post-procedural pharmacological regimens. Obviously I had to compromise, and finally the steering committee decided to use aspirin for at least one month in the experimental arm. Scientifically speaking, after 11 months of monotherapy without aspirin, the risk reduction of $21 \%$ in the experimental arm was demonstrated with a p-value of 0.028 , with a non-statistically significant reduction in bleeding (BARC 3 or 5) by $14 \%$. Furthermore, with Pedro Lemos, we are currently conducting a trial called ASET (Acetylsalicylic acid elimination trial: NCT03469856)! No aspirin post-PCI! The author clarified that it was their own comment, rather than mine. At least I had with him/ her a friendly exchange of e-mails.

As put in writing by Milton Packer, "for many physicians Twitter seemed to present the cutting edge of medical practice, the new 'evidence-based medicine' or EBM. If Twitter is your primary source of reliable and up-to-date medical and scientific information and discourse, then you practice EBM - emotionbased medicine. More precisely, you practice self-declared expertbased medicine. In reality, you practice opinion-based medicine".

I would not confess to know for sure the way to go with our journal on this issue of social media. As a clinical researcher, I had the reputation of being a fast "adopter", but in the present case I am somewhat reluctant. Probably a journal such as NEJM with a history of 206 years of publishing and an impact factor of 79.258 can afford to entertain its readership with Twitter, without any risk for the journal of being trivialised. The (thus far) hype to communicate with uncontrolled media, that has the speed of light and the ubiquity of the atmosphere surrounding us on earth, is tempting for publishers and editors. As a new kid on the block, and as editor of an emerging journal with a modest impact factor of 4.417 (13 years of existence for EuroIntervention vs. 206 years for NEJM), I am somewhat nervous about tweeting around the world... as far as our journal is concerned.

\section{References}

1. Shurlock B. The Socratic attic, where much of the future of the stent was hatched. Eur Heart J. 2012;33:2109-10.

2. Capodanno D. Twitterature. EuroIntervention. 2018;14: e959-61.

3. Kiemeneij F. Left distal transradial access in the anatomical snuffbox for coronary angiography (ldTRA) and interventions (ldTRI). EuroIntervention. 2017;13:851-7.

4. Lee JW, Park SW, Son JW, Ahn SJ, Lee SH. Real-world experience of the left distal transradial approach for coronary angiography and percutaneous coronary intervention: a prospective observational study (LeDRA). EuroIntervention. 2018;14: e995-1003.

5. Walsh MN. Social Media and Cardiology. J Am Coll Cardiol. 2018;71:1044-7.

6. Tofield A. Milton Packer MD. Eur Heart J. 2018;39:2126.

7. Byrne RA. Fallout from the ORBITA trial - is angioplasty in a spin? EuroIntervention. 2017;13:1253-4. 